\title{
Crescimento e rendimento de pimentão fertigado sob diferentes lâminas de irrigação e doses de potássio
}

\author{
Francimar da S. Albuquerque ${ }^{1}$, Ênio F. de F. e Silva ${ }^{1}$, \\ João A. C. de Albuquerque Filho ${ }^{1} \&$ Marcus F. F. N. N unes ${ }^{1}$
}

RESUMO

O bjetivou-se, com este trabalho, avaliar o crescimento e a produtividade da cultura do pimentão sob influência de lâminas de irrigação e doses de potássio. 0 delineamento experimental adotado foi inteiramente casualizado, em esquema fatorial $5 \times 2$, com quatro repetições, sendo cinco lâminas de irrigação $\left(80,90,100,110\right.$ e $120 \%$ da ETc) e duas doses de potássio (80 e $120 \mathrm{~kg} \mathrm{ha}^{-1}$ de $\mathrm{K}_{2} \mathrm{O}$ ), aplicadas parceladamente, de acordo com a fase fenológica, por intermédio de sistema de irrigação por gotejamento, com emissores autocompensantes, instalado em uma bateria de 40 lisímetros de drenagem cultivados com pimentão (híbrido Maximos F1), localizada no campus da U niversidade Federal Rural de Pernambuco (UFRPE), Recife, PE. O ciclo da cultura durou 142 dias; realizaram-se medições de altura e diâmetro do colo, variáveis de produção e estimativa do índice de área foliar ao final do ciclo. As variáveis de crescimento e de rendimento foram influenciadas pelas lâminas de irrigação e doses de potássio. Q uando se fixou a menor dose, a estimativa do maior número de frutos por planta, peso médio de frutos e produtividade ocorreram com o emprego da lâmina de irrigação de máxima eficiência equivalente a 96, 120 e $102 \%$ da ETc, respectivamente.

Palavras-chave: Capsicum annuum, ciclo fenológico, lisímetros de drenagem

\section{Growth and yield of sweet pepper fertigated under different irrigation depths and potassium doses}

\begin{abstract}
The objective of this study was to evaluate the growth and yield of sw eet pepper under the influence of irrigation levels and potassium doses. The experimental design consisted of a completely randomized $5 \times 2$ factorial scheme with four replications and five irrigation depths $(80,90,100,110$ and $120 \%$ of ETc) and two levels of potassium (80 and $120 \mathrm{~kg} \mathrm{ha}^{-1}$ of $\mathrm{K}_{2} \mathrm{O}$ ), applied in succession according to the phenological phase, through a system of drip irrigation with self-compensated emitters, installed in a set of 40 drainage lysimeters cultivated with sweet pepper (hybrid Maximos F1), located at campus of the Federal Rural U niversity of Pernambuco (U FRPE), Recife, PE. The crop cycle lasted 142 days; measurements were made for height, diameter and production variables and leaf area index estimated at the end of the cycle. The variables of growth and yield were influenced by the irrigation depths and potassium doses. When the low est dose was fixed, the estimate of more fruits per plant, fruit weight and yield occurred with the use of irrigation depth of maximum efficiency equivalent to 96,120 and 102\% ETc, respectively.
\end{abstract}

Key words: Capsicum annuum, phenological cycle, drainage lysimeters 


\section{INTRODUÇÃO}

O pimentão (Capsicum annuum L.), pertencente à família das Solanáceas, está entre as dez hortaliças de maior importância econômica no mercado hortifrutigranjeiro nacional, tanto em valor quanto em volume comercializado, sendo cultivado em todo o território nacional (Echer et al., 2002).

O pimentão se situa entre as culturas que apresentam grande utilização de híbridos, em virtude do elevado potencial de produção. Uma característica marcante nas cidades brasileiras de médio e grande porte é a existência de áreas denominadas "cinturões verdes", localizadas em seu perímetro urbano ou periurbano, onde se cultivam frutas e hortaliças que abastecem o mercado consumidor.

O uso de água pelas plantas e, portanto, todos os processos fisiológicos, estão diretamente relacionados ao seu status no sistema solo-água-planta-clima; sendo assim, o conhecimento das inter-relações entre esses fatores é fundamental para o planejamento e a operação de sistemas de irrigação para se obter máxima produção e boa qualidade do produto (Trani \& Carrijo, 2004). Na Região Nordeste do Brasil poucos são os trabalhos para determinação de lâminas de irrigação em áreas urbanas.

A utilização adequada dos recursos hídricos garante o aumento da produtividade; apesar disto, faz-se necessário o fornecimento de nutrientes para as culturas. Nos últimos anos, além da forma tradicional de aplicação de nutrientes tem sido adotada a fertigação, pois permite a aplicação de fertilizantes simultaneamente com a água de irrigação (Eloi et al., 2004), e uma das vantagens mais significativas é a eficiência de absorção de nutrientes pela planta, por torná-los prontamente disponíveis na solução do solo, fáceis de serem absorvidos (Marcussi, 2005). Tal uniformidade de distribuição dos nutrientes está diretamente relacionada com o coeficiente de uniformidade da água de irrigação (Trani \& Carrijo, 2004).

A reposição de água e nutrientes é essencial para o desenvolvimento adequado da planta e obtenção de produtividade satisfatória, na quantidade ideal e no momento oportuno (Nanetti et al., 2000). O conhecimento de práticas agrícolas, como adubação e seu efeito na nutrição mineral e na produção do pimentão, é oportuno para que os produtores utilizem, racional e economicamente, os fertilizantes.

Silva et al. (2001), destacam a importância do potássio no metabolismo do pimentão, que melhora as características físicas e químicas dos frutos em razão da otimização no processo de transpiração e formação de carboidratos. Subhani et al. (1990) e Vanangamudi et al. (1990) se referem a um efeito favorável dos nutrientes nitrogênio e potássio no comprimento e diâmetro dos frutos.

Medeiros et al. (2004), afirmam que o coeficiente de cultura (Kc) é um parâmetro relacionado aos fatores ambientais e fisiológicos das plantas devendo, preferencialmente, ser determinado para as condições locais nas quais será utilizado; todavia, sua determinação sob condições de campo exige um grande esforço de pessoal técnico, equipamentos e custos, em virtude da quantidade de informações, controles e monitoramentos necessários ao balanço hídrico em uma área irrigada. Para obtenção de Kc ao longo do ciclo da cultura, normalmente se utilizam lisímetros.

A quantidade de fertilizantes a se aplicar para qualquer cultura, deve ser a mais próxima possível do que é extraído pela mesma, pois existe o perigo de salinização do solo devido ao acúmulo de sais na região do sistema radicular.

A aplicação de fertilizantes junto à água de irrigação caracteriza a técnica denominada fertigação. O emprego dessa técnica tem possibilitado a otimização do uso de insumos em diferentes culturas irrigadas, tanto em aspectos relacionados à produtividade quanto à qualidade dos produtos obtidos, sendo mais notável sua adoção em culturas irrigadas por sistemas de irrigação localizada (Oliveira \& Villas Bôas, 2008).

Segundo Papadopoulos (1999), com um sistema de fertigação por gotejamento a absorção de N, P e K é substancialmente melhorada. A este respeito, por meio de unidade de fertilizantes e de água aplicada, maior produtividade e melhor qualidade são obtidas. Além disso, fertigação reduz as flutuações de salinidade da solução do solo, devido aos fertilizantes, melhorando as condições da solução do solo para as culturas particularmente sensíveis ao sal.

O estudo da necessidade de nutrientes em hortaliças tem recebido muita atenção, pois é de fundamental importância suprir as plantas com fertilizantes que não conduzam a um aumento excessivo da condutividade elétrica do solo ou do substrato, promovendo o melhor equilíbrio possível entre os mesmos.

O presente trabalho foi realizado com o objetivo de avaliar o crescimento e o rendimento da cultura do pimentão sob influência de diferentes lâminas de irrigação e doses de potássio na Região Metropolitana do Recife, de forma a permitir um manejo adequado.

\section{Material E MÉTODOS}

O experimento foi conduzido na Estação Lisimétrica do Departamento de Tecnologia Rural (DTR), situada no Campus da Universidade Federal Rural de Pernambuco (UFRPE), em Recife, PE, cujas coordenadas geográficas no sistema SAD 69 (South American Datum), são $8^{\circ} 01^{\prime}$ 05" de latitude sul e 34 56' $48^{\prime \prime}$ de longitude oeste e altitude de 6,49 m.

O clima, de acordo com a classificação de Koppen, é As, megatérmico tropical (tropical úmido), com temperatura média do mês mais frio superior a $18^{\circ} \mathrm{C}$ com precipitações de outono e inverno.

A estrutura experimental possui dimensão que totaliza 464,40 $\mathrm{m}^{2}$ de área plantada, possuindo uma bateria de 40 lisímetros de drenagem, preenchidos com solo de textura arenosa. Cada lisímetro se constituía de caixa de cimento reforçado com fio sintético-CRFS (linha Brasiflex - Brasilit), troncônicas, com capacidade de $1.000 \mathrm{~L}$, diâmetro externo na borda superior 1.380 mm e altura externa de $745 \mathrm{~mm}$ (Albuquerque Filho et al., 2009).

O sistema de drenagem dos lisímetros é constituído de um segmento de tubo de polietileno de $25 \mathrm{~mm}$ de diâmetro, disposto ao longo da circunferência, junto ao fundo da caixa. Esses tubos têm perfurações de $5 \mathrm{~mm}$ de diâmetro a cada $5 \mathrm{~cm}$; uma camada de brita zero de aproximadamente $5 \mathrm{~cm}$ de espessura; 
Tabela 1. Coeficiente de uniformidade de Christiansen (CUC) e de uniformidade de distribuição (CUD) para as doses $\mathrm{D}_{1}$ $\left(80 \mathrm{~kg} \mathrm{ha}^{-1} \mathrm{~K}_{2} \mathrm{O}\right)$ e $\mathrm{D}_{2}\left(120 \mathrm{~kg} \mathrm{ha}^{-1} \mathrm{~K}_{2} \mathrm{O}\right)$

\begin{tabular}{|c|c|c|c|c|c|c|c|c|}
\hline \multirow{2}{*}{ Variável } & \multicolumn{2}{|c|}{ CUC (\%) aos 60 dias } & \multicolumn{2}{|c|}{ CUD (\%) aos 60 dias } & \multicolumn{2}{|c|}{ CUC (\%) aos 120 dias } & \multicolumn{2}{|c|}{ CUD (\%) aos 120 dias } \\
\hline & $D_{1}$ & $D_{2}$ & $D_{1}$ & $D_{2}$ & $D_{1}$ & $D_{2}$ & $D_{1}$ & $D_{2}$ \\
\hline Água & 97,39 & 97,39 & 95,64 & 95,64 & 94,75 & 94,75 & 92,19 & 92,19 \\
\hline CE & 89,53 & 89,24 & 82,46 & 82,69 & 85,74 & 87,33 & 80,18 & 81,65 \\
\hline $\mathrm{K}^{+}$ & 87,09 & 84,45 & 79,32 & 73,20 & 85,65 & 85,65 & 83,03 & 81,92 \\
\hline
\end{tabular}

CE - condutividade elétrica, $\mathrm{K}^{+}$- concentração de potássio

uma camada de areia lavada de aproximadamente $3 \mathrm{~cm}$ de espessura e uma tubulação que interliga o sistema de drenagem à unidade de coleta e medição do efluente. Conjugado a cada sistema de drenagem existe um piezômetro individual com escala milimétrica, para medir a variação de nível da água dentro dos respectivos lisímetros.

O delineamento experimental adotado foi inteiramente casualizado, em esquema fatorial 5 x 2, com quatro repetições, sendo cinco lâminas de irrigação (80, 90, 100, 110 e $120 \%$ da ETc) e duas doses de potássio (80 e $120 \mathrm{~kg} \mathrm{ha}^{-1}$ de $\left.\mathrm{K}_{2} \mathrm{O}\right)$, aplicadas de forma parcelada, de acordo com a fase fenológica da cultura.

A aplicação da fertigação nos lisímetros era feita por intermédio de sistema de irrigação por gotejamento, compreendendo três emissores autocompensantes, online, modelo Katif, tipo botão de fabricação Plastro. A vazão unitária do emissor especificada pelo fabricante é de $3,75 \mathrm{~L} \mathrm{~h}^{-1}$, sendo a medida 3,90 $\mathrm{L} \mathrm{h}^{-1}$, com pressão de serviço de 0,80 a 3,00 bar.

Foram determinados a uniformidade de aplicação das doses de potássio, e seu relacionamento com a uniformidade da distribuição da água, utilizando-se o coeficiente de uniformidade de Christiansen (CUC) e o coeficiente de uniformidade de distribuição (CUD), propostos por Bernardo et al. (2008); realizaram-se duas coletas, aos 60 e 120 dias, após a implantação da cultura.

Os resultados dos parâmetros de uniformidade CUC e CUD obtidos se encontram na Tabela 1, para ambas as doses de potássio, caracterizando o desempenho do sistema em ótimas condições.

Os lisímetros foram cultivados com pimentão (híbrido Maximos F1 - EliSem, Clause Vegetable Seeds), cuja parcela experimental foi composta de três plantas em cada lisímetro, com espaçamento de $0,40 \mathrm{~m}$ entre plantas na linha e $1,30 \mathrm{~m}$ entre linhas. As mudas de pimentão foram adquiridas em produtor credenciado no Ministério da Agricultura, Pecuária e Abastecimento (MAPA).

A fim de minimizar o efeito de advecção sobre as plantas nos lisímetros, mudas de pimentão do mesmo híbrido foram plantadas na área entre os lisímetros, utilizando o mesmo espaçamento; aos 80 dias após o transplante fez-se o tutoramento em espaldeira simples.

A irrigação foi realizada diariamente, e as lâminas estimadas com base na ETc, Eq. 1:

$$
\mathrm{ETc}=\mathrm{ETo} \times \mathrm{Kc} \times \mathrm{Kl}_{\text {méd }}
$$

em que:

ETc - evapotran spiração da cultura, $\mathrm{mm} \mathrm{d}^{-1}$

ETo- evapotranspiração de referência de Penman-Monteith, $\mathrm{mm} \mathrm{d}^{-1}$
Kc - coeficiente de cultivo, adimensional

$\mathrm{Kl}_{\text {méd }}$ - coeficiente de localização médio, adimensional

Para determinação do $\mathrm{K}_{\text {méd. }}$, utilizou-se a média de quatro valores de coeficiente de localização, segundo Pizarro (1996). Os valores de $\mathrm{Kl}$ dependem do valor da fração de área sombreada pelo cultivo (S) a qual foi estimada conforme metodologia preconizada pelo mesmo autor.

A ETo e a precipitação foram obtidas na estação meteorológica automatizada, provida de sensores e acessórios necessários para determinação da ETo de Penman-Monteith (Campbell Scientific modelo CR1000/CFM100/OS100), utilizadas na estimativa das lâminas de irrigação, de acordo com os tratamentos utilizados.

Os valores de Kc utilizados diariamente respaldados na fase fenológica da cultura, foram: 0,40 (da emergência até $10 \%$ do desenvolvimento - 30 dias); 0,70 (10\% do desenvolvimento até $75 \%$ do desenvolvimento - 40 dias); 1,05 (floração até o início da maturação - 60 dias), e 0,85 (da maturação até a última colheita - 20 dias), de acordo com Doorenbos \& Pruitt (1977).

Os adubos utilizados na fertigação foram fosfato monoamônico purificado (MAP - $\left.\mathrm{NH}_{4} \mathrm{H}_{2} \mathrm{PO}_{4}\right)(11 \%$ de N e $60 \%$ de $\left.\mathrm{P}_{2} \mathrm{O}_{5}\right)$, nitrato de cálcio $\left(\mathrm{Ca}\left(\mathrm{NO}_{3}\right)_{2}\right)(15,5 \%$ de $\mathrm{N}$ e $20 \%$ de cálcio), sulfato de magnésio $\left(\mathrm{Mg}\left(\mathrm{SO}_{4}\right)_{2} .7 \mathrm{H}_{2} \mathrm{O}\right)(9,5 \%$ de $\mathrm{Mg}$ e $12 \%$ de $\mathrm{S})$ e cloreto de potássio $(\mathrm{KCl})\left(60 \% \mathrm{~K}_{2} \mathrm{O}\right)$, fazendo-se o balanceamento necessário de nutrientes.

As doses diárias de nitrogênio, fósforo, cálcio, magnésio e potássio aplicadas via fertigação, seguiram recomendações de Trani \& Carrijo (2004), ressalvando-se que as dosagens de potássio foram ajustadas aos tratamentos do experimento (Tabela 2).

Tabela 2. Recomendação diárias de nutrientes para o pimentão, conforme a fase de desenvolvimento da cultura

\begin{tabular}{|c|c|c|c|c|c|c|c|}
\hline \multirow{2}{*}{$\begin{array}{c}\text { Dias após } \\
\text { transplante } \\
\text { (DAT) }\end{array}$} & \multirow{2}{*}{$\begin{array}{l}\text { Fases } \\
\text { (dias) }\end{array}$} & \multicolumn{6}{|c|}{ Quantidade dos nutrientes $\left(\mathrm{kg} \mathrm{ha}^{-1} \mathrm{~d}^{-1}\right)$} \\
\hline & & $\mathbf{N}$ & $\mathbf{P}_{2} \mathrm{O}_{5}$ & $\mathrm{Ca}$ & $\mathrm{Mg}$ & $\begin{array}{l}\mathrm{K}_{2} \mathrm{O} \\
\left(\mathrm{D}_{1}\right)\end{array}$ & $\begin{array}{l}\mathrm{K}_{2} \mathrm{O} \\
\left(\mathrm{D}_{2}\right)\end{array}$ \\
\hline 1 & 5 & 0,05 & 0,01 & 0,03 & 0,04 & 0,01 & 0,02 \\
\hline 5 & 15 & 0,35 & 0,06 & 0,23 & 0,14 & 0,12 & 0,18 \\
\hline 20 & 20 & 1,16 & 0,24 & 0,69 & 0,50 & 0,35 & 0,52 \\
\hline 40 & 20 & 1,32 & 0,22 & 0,67 & 0,70 & 0,40 & 0,61 \\
\hline 60 & 20 & 2,63 & 0,77 & 1,93 & 1,05 & 0,74 & 1,12 \\
\hline 80 & 30 & 2,73 & 0,60 & 0,80 & 0,75 & 0,86 & 1,28 \\
\hline 110 & 40 & 3,75 & 1,10 & 1,00 & 0,72 & 0,75 & 1,13 \\
\hline 150 & 10 & 2,00 & 0,90 & 1,20 & 0,90 & 0,56 & 0,84 \\
\hline
\end{tabular}

Além dos macronutrientes, foram realizadas duas aplicações de Quelatec AZ, uma mistura sólida de micronutrientes essenciais quelatizados com EDTA, na dosagem de 2,50 $\mathrm{kg} \mathrm{ha}^{-1}$ recomendada para pimentão, aos 70 e aos 90 dias após o 
transplante (DAT) e adubações foliares durante o ciclo, aplicando-se o produto $\mathrm{CaB} 10$, com a finalidade de fornecer $\mathrm{Ca}$ e B, importantes na fase de frutificação. Além de adubações foliares foram aplicados Confidor $700 \mathrm{WG}$ e Vertimec $18 \mathrm{EC}$, para controle de pulgões e ácaros, respectivamente.

Mediu-se a altura das plantas a cada 7 dias, desde o transplante até o último dia de tratamento, com o auxílio de uma régua $(0,1 \mathrm{~cm})$, enquanto o diâmetro do colo teve suas avaliações realizadas a cada 15 dias, com apoio de um paquímetro $(0,05 \mathrm{~mm})$.

$\mathrm{Na}$ estimativa da área foliar, ao final do ciclo (142 dias), obtiveram-se comprimento e largura de três folhas, tomadas aleatoriamente por planta, sendo a primeira folha tomada na parte superior, a segunda na parte mediana e a terceira na parte inferior da copa da planta, obtendo-se, assim, comprimento e largura médios.

Para estimativa da área da folha utilizou-se a seguinte equação de regressão, obtida por Rezende et al. (2002), cujo coeficiente de determinação $\left(\mathrm{R}^{2}\right)$ foi de 0,9910 , quando avaliaram o efeito da lâmina de água aplicada na altura, diâmetro do caule e área foliar de plantas de pimentão, híbrido Zarco.

$$
Y=0,5979 X
$$

em que:

Y - área da folha, $\mathrm{cm}^{2}$

$\mathrm{X}$ - área correspondente ao produto do comprimento (C) pela largura (L) da folha, $\mathrm{cm}^{2}$

Obteve-se a área foliar multiplicando-se a área da folha pelo número total de folhas, por planta. O Índice de Área Foliar (IAF) foi estimado dividindo-se a área foliar estimada pela área de solo ocupada pelas plantas $\left(\mathrm{E}_{\mathrm{L}} \times \mathrm{E}_{\mathrm{P}}\right)$.

As variáveis de produção avaliadas nos frutos ao longo de cinco colheitas, foram comprimento de frutos $(\mathrm{CF})$, diâmetro de frutos (DF), espessura de casca (EC) (medidos com o auxílio de um paquímetro $(0,05 \mathrm{~mm}))$, número de frutos por planta (NFP), peso médio de frutos (PMF) (utilizando uma balança de precisão $(0,01 \mathrm{~g}))$, e a produtividade $(\mathrm{P})$.
Os dados foram analisados no sistema computacional SISVAR Versão 5.3 (Ferreira, 2008) e interpretados por meio das significâncias das análises de variância e regressão, considerando-se o nível de probabilidade de até $5 \%$ pelo teste $\mathrm{F}$.

Para estabelecer o modelo que representasse o fenômeno em estudo, utilizou-se o teste " $t$ " de Student para verificar os coeficientes de regressão, adotando-se o nível de probabilidade de $10 \%$, e os coeficientes de determinação $\mathrm{R}^{2}$.

A apresentação das equações de regressão e suas interpretações obedeceram a recomendação de Alvarez \& Alvarez (2003). A lâmina ótima foi estimada a partir dos modelos de regressão, obtendo-se, pela derivada primeira, o ponto de máxima produtividade.

\section{RESULTADOS E DISCUSSÃO}

Verifica-se, na Tabela 3, efeito significativo em níveis de significância variando de 5 a $0,1 \%$ de probabilidade da interação lâmina (L) x dose (D) e dos fatores isolados L e D para altura de plantas (AP), ao longo dos dias de experimento.

Verifica-se ainda, nesta tabela, efeito significativo da interação L x D com níveis de significância variando de 1 a $0,1 \%$ de probabilidade da variável AP, ao longo dos dias de avaliação, exceto aos 7, 21, 28 e 35 DAT.

Quanto ao efeito isolado dos fatores L e D, observa-se que houve influência em níveis de significância, variando de 5 a $0,1 \%$, exceto aos 7, 14 e 21 DAT. Na mesma tabela, se observam coeficientes de variação menores que $10 \%$, indicando boa precisão dos dados constatados no experimento, além de que a diferenciação da altura de plantas ocorreu a partir dos 14 DAT.

Constata-se, na Tabela 4, efeito significativo em níveis de significância variando de 5 a $0,1 \%$ de probabilidade da interação L x D e dos fatores isolados L e D para diâmetro do colo (DC) ao longo do experimento; por outro lado, o efeito significativo da interação L x D, com níveis de significância de 5 e $0,1 \%$ de probabilidade do DC aos 21, 35, 63, 77, 91, 105 e 112 DAT, também é notado; quanto ao efeito isolado dos fatores L e D, houve influência significativa com níveis de probabilidade

Tabela 3. Resumo da AN O VA para altura de plantas (AP), medida ao longo do ciclo, em dias, sob efeito dos tratamentos

\begin{tabular}{|c|c|c|c|c|c|c|c|c|c|}
\hline \multirow{2}{*}{$\begin{array}{l}\text { Fonte de } \\
\text { variação }\end{array}$} & \multirow{2}{*}{ GL } & \multicolumn{8}{|c|}{ Quadrados médios } \\
\hline & & 7 & 14 & 21 & 28 & 35 & 42 & 49 & 56 \\
\hline $\begin{array}{l}\text { L (\%ETc) } \\
D\left(\mathrm{~kg} \mathrm{ha}^{-1}\right) \\
\mathrm{L} \times \mathrm{D} \\
\text { Resíduo }\end{array}$ & $\begin{array}{c}4 \\
1 \\
4 \\
30\end{array}$ & $\begin{array}{c}0,77^{\text {ns }} \\
0,50^{\text {ns }} \\
0,84^{\text {ns }} \\
0,46\end{array}$ & $\begin{array}{c}0,26^{\mathrm{ns}} \\
0,02^{\mathrm{ns}} \\
2,15^{*} \\
0,54 \\
\end{array}$ & $\begin{array}{c}2,72^{\mathrm{ns}} \\
1,95^{\mathrm{ns}} \\
4,00^{\mathrm{ns}} \\
1,50\end{array}$ & $\begin{array}{c}0,87^{\text {ns }} \\
13,78^{*} \\
5,49^{\text {ns }} \\
2,40 \\
\end{array}$ & $\begin{array}{c}1,86^{\mathrm{ns}} \\
22,48^{* *} \\
1,15^{\mathrm{ns}} \\
2,22 \\
\end{array}$ & $\begin{array}{c}13,97^{\mathrm{ns}} \\
91,88^{*} * * \\
44,25 * * * \\
5,64\end{array}$ & $\begin{array}{c}31,23 * * \\
96,79 * * * \\
43,25 * * * \\
6,65 \\
\end{array}$ & $\begin{array}{c}46,25^{* *} \\
179,12^{* * *} \\
101,86^{* * *} \\
8,71 \\
\end{array}$ \\
\hline CV\% & & 5,98 & 6,23 & 9,06 & 9,18 & 6,63 & 8,48 & 7,70 & 8,58 \\
\hline \multirow{2}{*}{$\begin{array}{l}\text { Fonte de } \\
\text { variação }\end{array}$} & \multirow{2}{*}{ GL } & \multicolumn{8}{|c|}{ Quadrados médios } \\
\hline & & 63 & 70 & 77 & 84 & 91 & 98 & 105 & 112 \\
\hline $\begin{array}{l}\text { L (\%ETc) } \\
D\left(\mathrm{~kg} \mathrm{ha}^{-1}\right) \\
\mathrm{L} \times \mathrm{D} \\
\text { Resíduo }\end{array}$ & $\begin{array}{c}4 \\
1 \\
4 \\
30\end{array}$ & $\begin{array}{c}60,06 * * * \\
99,96 * * * \\
76,47 * * * \\
6,86 \\
\end{array}$ & $\begin{array}{c}45,18 * * * \\
21,09 \text { ns } \\
60,68 * * * \\
6,46\end{array}$ & $\begin{array}{c}22,62^{* * *} * \\
1,77^{\mathrm{ns}} \\
35,97^{*} * * \\
3,49\end{array}$ & $\begin{array}{c}15,07 * * \\
24,75^{*} \\
66,61 * * * \\
3,58\end{array}$ & $\begin{array}{c}28,11^{* *} \\
169,49 * * * \\
63,72 * * * \\
4,56\end{array}$ & $\begin{array}{c}35,14 * * * \\
412,59 * * * \\
85,11 * * * \\
1,90\end{array}$ & $\begin{array}{c}99,09 * * * \\
173,63 * * \\
142,10 * * * \\
14,59\end{array}$ & $\begin{array}{c}86,35^{*} \\
157,45^{*} \\
168,86^{* * *} * \\
24,84\end{array}$ \\
\hline CV\% & & 7,25 & 7,13 & 5,22 & 5,00 & 5,31 & 3,17 & 8,05 & 9,81 \\
\hline
\end{tabular}

ns - Não significativo até $5 \%$

$*, * *$ e $* * *$ Significativos a 5,1 e $0,1 \%$ de probabilidade, respectivamente, pelo teste $\mathrm{F}$

L, D, GL, CV: Lâmina, Dose, Grau de Liberdade e Coeficiente de Variação 
Tabela 4. Resumo da ANO VA para diâmetro do colo (DC), medido ao longo do ciclo, em dias, sob efeito dos tratamentos

\begin{tabular}{|c|c|c|c|c|c|c|c|c|c|c|}
\hline \multirow{2}{*}{$\begin{array}{l}\text { Fonte de } \\
\text { Variação }\end{array}$} & \multirow{2}{*}{ GL } & \multicolumn{9}{|c|}{ Quadrados médios } \\
\hline & & 7 & 21 & 35 & 49 & 63 & 77 & 91 & 105 & 112 \\
\hline L (\%ETc) & 4 & $0,01^{\mathrm{ns}}$ & $0,24^{\text {ns }}$ & $1,35^{* *}$ & $0,69^{\text {ns }}$ & $0,85^{\text {ns }}$ & $0,81^{\text {ns }}$ & $1,47^{\mathrm{ns}}$ & $7,08 * *$ & $3,15^{\text {ns }}$ \\
\hline $\mathrm{D}\left(\mathrm{kg} \mathrm{ha}^{-1}\right)$ & 1 & $0,02^{\text {ns }}$ & $0,16^{\text {ns }}$ & $8,36 * * *$ & $0,04^{\text {ns }}$ & $0,01^{\mathrm{ns}}$ & $0,12^{\mathrm{ns}}$ & $3,19 *$ & $4,67^{\mathrm{ns}}$ & $4,39^{\text {ns }}$ \\
\hline$L \times D$ & 4 & $0,01^{\text {ns }}$ & $0,61 * *$ & $2,75^{* * *}$ & $0,75^{\mathrm{NS}}$ & $1,66^{*}$ & $2,63 * * *$ & $2,37 *$ & $3,81^{*}$ & $5,62^{*}$ \\
\hline Resíduo & 30 & 0,01 & 0,11 & 0,25 & 0,70 & 0,55 & 0,38 & 0,64 & 1,22 & 1,61 \\
\hline CV\% & & 3,51 & 12,02 & 7,69 & 9,50 & 8,18 & 6,55 & 7,93 & 8,98 & 9,91 \\
\hline
\end{tabular}

ns - Não significativo até $5 \%$

$*, * *$ e *** Significativos a 5,1 e $0,1 \%$ de probabilidade, respectivamente, pelo teste $\mathrm{F}$

L, D, GL, CV: Lâmina, Dose, Grau de Liberdade e Coeficiente de Variação

variando de 5 a $0,1 \%$ apenas aos 35, 91 e 105 DAT. Na Tabela 4 se observam coeficientes de variação menores que $13 \%$, indicando boa precisão dos dados indicados no experimento. Pode-se observar, ainda, que a diferenciação do diâmetro colo teve início aos 35 DAT.

Desta forma, foi realizado o desdobramento da interação L x D para as variáveis AP e DC.

Na Figura 1A e B é possível constatar o comportamento das variáveis AP e DC das 120 plantas, considerando todas as unidades experimentais, sob efeitos dos tratamentos, ao longo dos dias de experimento, além do comportamento crescente para ambas as variáveis, com pequenas variações no tempo. Para a variável AP observam-se alternâncias de crescimento e decrescimento, causadas pelo peso dos frutos nas plantas na época de frutificação, entre 42 e 77 DAT, aproximadamente, devido a uma inclinação dos ramos, visto que o pimentão apresenta hábito de crescimento dicotômico (bifurcação dos ramos).

Nas Tabelas 5 e 6 estão apresentadas, para as variáveis AP e DC, medidas ao longo dos dias de experimentação, as equações de regressão ajustadas aos dados médios e seus respectivos coeficientes de determinação $\left(\mathrm{R}^{2}\right)$.

Tabela 5. Equações de regressão ajustadas aos dados médios de altura (AP) ao longo dos dias de experimento, em função das lâminas de irrigação estimadas nos níveis das doses de potássio de $80 \mathrm{~kg} \mathrm{ha}^{-1}$ de $\mathrm{K}_{2} \mathrm{O}\left(\mathrm{D}_{1}\right)$ e 120 $\mathrm{kg} \mathrm{ha}^{-1}$ de $\mathrm{K}_{2} \mathrm{O}\left(\mathrm{D}_{2}\right)$, com os respectivos coeficientes de determinação $\left(\mathrm{R}^{2}\right)^{2}$

\begin{tabular}{rcc}
\hline DAT & Equações de regressão ajustadas & $\mathbf{R}^{2}$ \\
14 & $\mathrm{AP}_{\mathrm{D} 2}=-17,10+0,58 * *(\% \mathrm{ETC})$ & 0,6625 \\
42 & $\mathrm{AP}_{\mathrm{D} 2}=39,54-0,10 \%(\% \mathrm{ETC})$ & 0,4304 \\
49 & $\mathrm{AP}_{\mathrm{D} 1}=43,83-0,12 * *(\% \mathrm{ETC})$ & 0,5602 \\
63 & $\mathrm{AP}_{\mathrm{D} 1}=-41,48+1,59 *(\% \mathrm{ETC})-0,0081 *(\% \mathrm{ETC})^{2}$ & 0,5124 \\
77 & $\mathrm{AP}_{\mathrm{D} 1}=109,68-1,54 * *(\% \mathrm{ETC})+0,0078 * *(\% \mathrm{ETC})^{2}$ & 0,4126 \\
91 & $\mathrm{AP}_{\mathrm{D} 1}=124,71-1,91 * *(\% \mathrm{ETC})+0,0102 * *(\% \mathrm{ETC})^{2}$ & 0,5531 \\
105 & $\mathrm{AP}_{\mathrm{D} 1}=245,58-4,18 * * *(\% \mathrm{ETC})+0,021 * * *(\% \mathrm{ETC})^{2}$ & 0,7156 \\
105 & $\mathrm{AP}_{\mathrm{D} 2}=73,85-0,24 * * *(\% \mathrm{ETC})$ & 0,4179 \\
\hline
\end{tabular}

$0, *, * *$ e *** Significativos a $10 \% ; 5 \% ; 1 \%$ e $0,1 \%$ de probabilidade, respectivamente, pelo teste $t$ AP - Altura de Plantas

DAT - Dias Após Transplante

Para os demais dias de observação após o transplante, os dados observados das variáveis AP e DC não apresentaram ajuste adequado aos modelos linear ou quadrático.

Esses resultados foram diferentes dos de Macêdo \& Alvarenga (2005), que não verificaram influência significativa da fertilização com potássio nem efeito interativo entre lâminas de água e doses de potássio sobre o crescimento das plantas

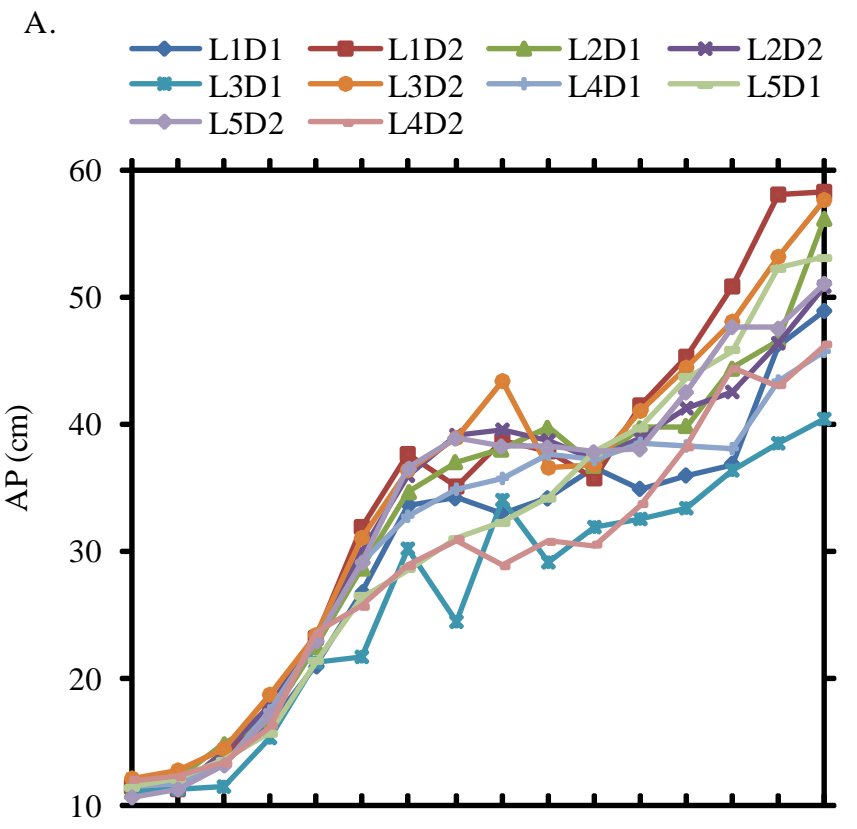

B.

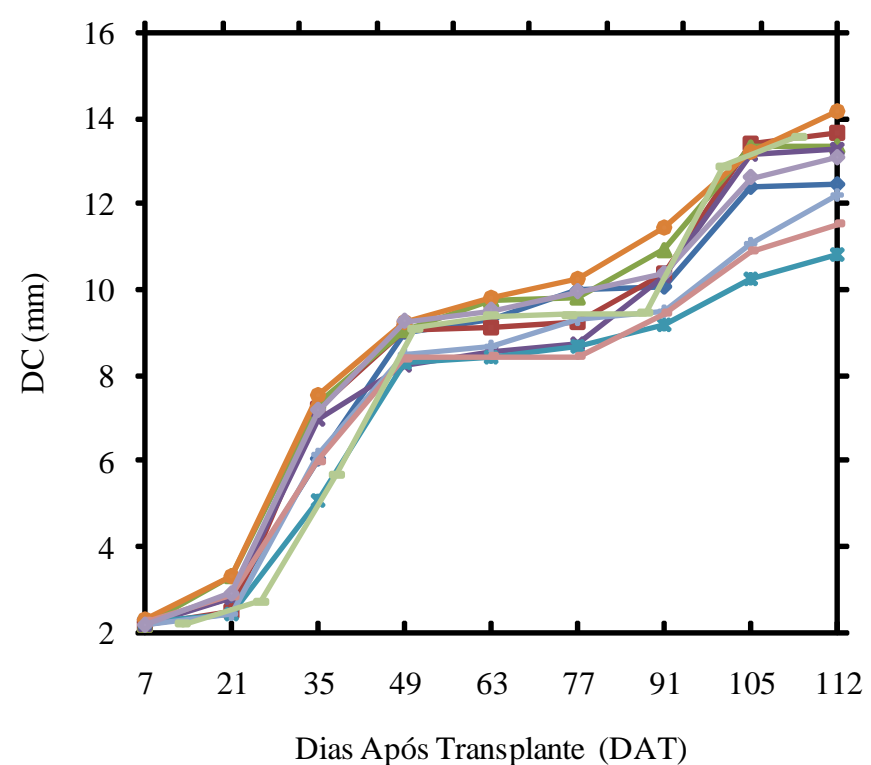

Figura 1. Altura de plantas (AP) (A) a cada 7 dias, e diâmetro do colo (DC) (B) a cada 15 dias, ao longo do ciclo fenológico do cultivo do pimentão, sob efeito dos tratamentos

até 90 dias de idade, ao estudarem os efeitos da aplicação de lâminas de água e doses de potássio, via fertigação por 
Tabela 6. Equações de regressão ajustadas aos dados médios de DC, ao longo dos dias de experimento, em função das lâminas de irrigação estimadas nos níveis das doses de potássio de $80 \mathrm{~kg} \mathrm{ha}^{-1} \mathrm{de} \mathrm{K}_{2} \mathrm{O}\left(\mathrm{D}_{1}\right)$ e $120 \mathrm{~kg} \mathrm{ha}^{-1}$ de $\mathrm{K}_{2} \mathrm{O}\left(\mathrm{D}_{2}\right)$ com os respectivos coeficientes de determinação $\left(R^{2}\right)$

\begin{tabular}{ccc}
\hline DAT & Equações de regressão ajustadas & $\mathbf{R}^{2}$ \\
21 & $\mathrm{DC}_{\mathrm{D} 2}=-8,06+0,21^{*}(\% \mathrm{ETC})-0,0010^{*}(\% \mathrm{ETC})^{2}$ & 0,6593 \\
77 & $\mathrm{DC}_{\mathrm{D} 1}=27,57-0,35^{*}(\% \mathrm{ETC})+0,0017 *(\% \mathrm{ETC})^{2}$ & 0,6041 \\
\hline
\end{tabular}

* Significativo a $5 \%$ de probabilidade pelo teste $t$

DC - Diâmetro do Colo

DAT - Dias Após Transplante

gotejamento, sobre o crescimento, a produção e a qualidade dos frutos do tomateiro. Entretanto, observaram efeito linear significativo de lâminas de água sobre o crescimento de plantas de tomate aos 30 dias de idade e sobre o comprimento de plantas aos 60 e 90 dias.

$\mathrm{Na}$ Tabela 7 verifica-se efeito significativo em níveis de probabilidade variando de 5 a $0,1 \%$ da interação $L \times$ e dos fatores isolados L e D nas variáveis de produção do pimentão, exceto para diâmetro do fruto (DF) e espessura de casca (EC).

Por esta tabela também se nota efeito significativo da interação L x D com níveis de significância $0,1 \%$ de probabilidade para todas as variáveis, exceto comprimento do fruto (CF), DF e EC; verifica-se, ainda, influência significativa do efeito isolado dos fatores $\mathrm{L}$ e $\mathrm{D}$ em níveis de significância variando de 5 a $0,1 \%$ de probabilidade para todas as variáveis, exceto DF e EC.

Nas Figuras 2A e 2B estão apresentados os modelos lineares que se ajustaram aos dados médios do índice de área foliar, em função das lâminas crescentes e doses de potássio. O máximo IAF foi obtido na lâmina $\mathrm{L}_{5}$, fixando-se ambas as doses de potássio.

Houve incrementos de $154,50 \%$ ao se comparar os respectivos valores estimados do IAF com os obtidos na lâmina $\mathrm{L}_{1}\left(0,30 \mathrm{~m}^{2} \mathrm{~m}^{-2}\right)$ e na lâmina $\mathrm{L}_{5}\left(0,76 \mathrm{~m}^{2} \mathrm{~m}^{-2}\right)$, para a dose $\mathrm{D}_{1}$ de potássio; no segundo caso, o incremento foi de $136,76 \%$ quando comparado com os dados estimados na lâmina $\mathrm{L}_{1}(0,32$ $\left.\mathrm{m}^{2} \mathrm{~m}^{-2}\right)$ e na lâmina $\mathrm{L}_{5}\left(0,76 \mathrm{~m}^{2} \mathrm{~m}^{-2}\right)$.

Esses resultados permitem inferir que plantas em condições de déficit apresentam área foliar reduzida, tornando-se a primeira linha de defesa em condições de restrição de água e, consequentemente, apresentarão IAF também reduzido, condição apresentada pelas plantas submetidas à lâmina $\mathrm{L}_{1}$.

Pela Figura 3A e B, tem-se a variação dos dados médios observados do número de frutos por planta (NFP), além dos

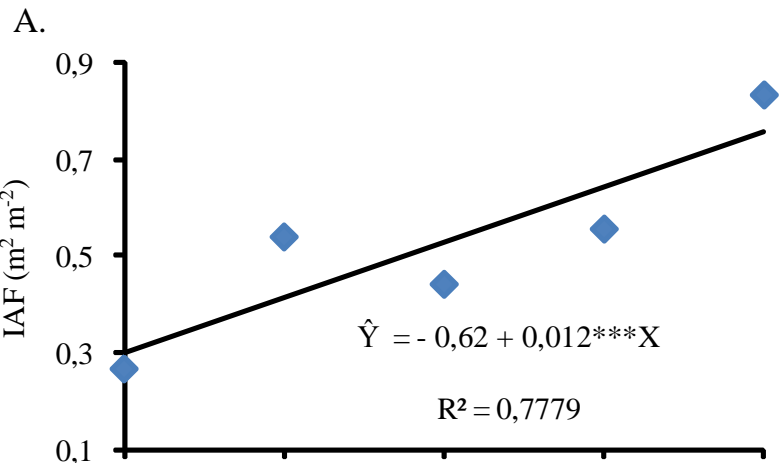

B.

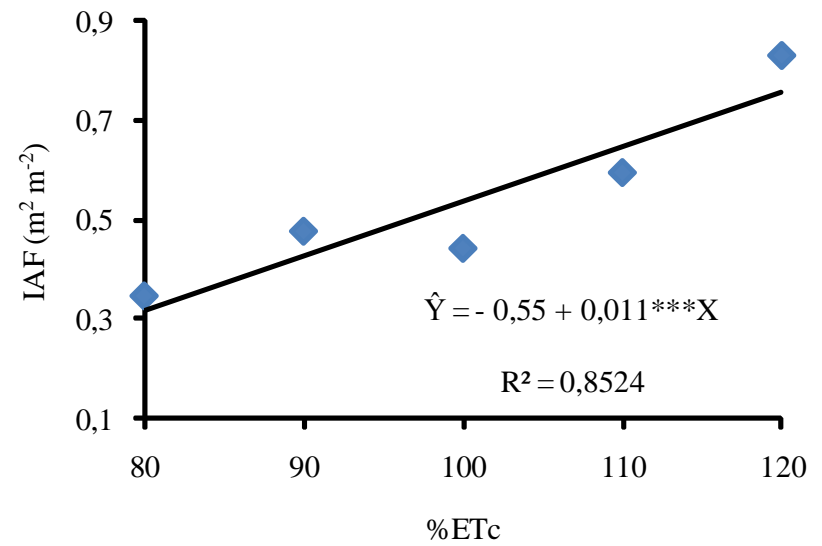

Figura 2. Dados médios observados e estimados pelo model o na variável Índice de Área Foliar (IAF), em função de lâminas de irrigação, estimada nos níveis da dose de potássio $D_{1}\left(80 \mathrm{~kg} \mathrm{ha}^{-1} \mathrm{~K}_{2} \mathrm{O}\right)(\mathrm{A})$ e dose de potássio $\mathrm{D}_{2}$ (120 kg ha-1 $\left.\mathrm{K}_{2} \mathrm{O}\right)(\mathrm{B})$

dados estimados obtidos com as equações de regressão, em função da variação de lâminas crescentes de irrigação com base na evapotranspiração da cultura (\%ETc), e das doses de potássio.

A média do número de frutos por planta (NFP) encontrada, foi de 6,51. Na Figura 3A tem-se o modelo quadrático que se ajustou aos valores para o número total de frutos por planta, em função das lâminas crescentes, quando se fixou a dose de potássio $80 \mathrm{~kg} \mathrm{ha}^{-1}\left(\mathrm{D}_{1}\right)$.

Pela derivada primeira da equação de regressão, estimou-se a lâmina de $95,76 \%$ da ETc como aquela responsável pelo máximo número de frutos por planta; houve incrementos de 27,96 e 106,99\% quando se comparam os respectivos valores máximos estimados com os obtidos na lâmina $\mathrm{L}_{1}$ de 6,45 frutos por planta, e na lâmina $\mathrm{L}_{5}$ de 3,99 frutos por planta.

Tabela 7. Resumo da AN OVA para índice de área foliar (IAF), comprimento de fruto (CF), diâmetro de fruto (DF), espessura de casca (EC), número de frutos por planta (NFP), peso médio de frutos (PMF) e produtividade (P)

\begin{tabular}{|c|c|c|c|c|c|c|c|c|}
\hline \multirow{2}{*}{ Fonte de variação } & \multirow{2}{*}{ GL } & \multicolumn{7}{|c|}{ Quadrados médios } \\
\hline & & IAF & CF & DF & EC & NFP & PMF & $\mathbf{P}$ \\
\hline L (\%ETc) & 4 & $0,30 * * *$ & $0,24^{\mathrm{ns}}$ & $0,04^{\mathrm{ns}}$ & $0,001^{\mathrm{ns}}$ & $3,93 *$ & $337,98 * * *$ & $103,12 * * *$ \\
\hline $\mathrm{D}\left(\mathrm{kg} \mathrm{ha}^{-1}\right)$ & 1 & $0,0007^{\mathrm{ns}}$ & $4,50 * *$ & $0,0003^{\mathrm{ns}}$ & $0,00006^{\mathrm{ns}}$ & $1,11^{\text {ns }}$ & $10,27^{\mathrm{NS}}$ & $13,37 * *$ \\
\hline LxD & 4 & $0,01 * * *$ & $0,19^{\text {NS }}$ & $0,05^{\mathrm{ns}}$ & $0,003^{\mathrm{NS}}$ & $13,58 * * *$ & $854,04 * * *$ & $25,85 * * *$ \\
\hline Resíduo & 30 & 0,0005 & 0,36 & 0,10 & 0,002 & 1,46 & 27,84 & 1,56 \\
\hline $\mathrm{CV} \%$ & & 4,12 & 6,71 & 5,99 & 11,40 & 18,55 & 7,21 & 6,73 \\
\hline
\end{tabular}


A.

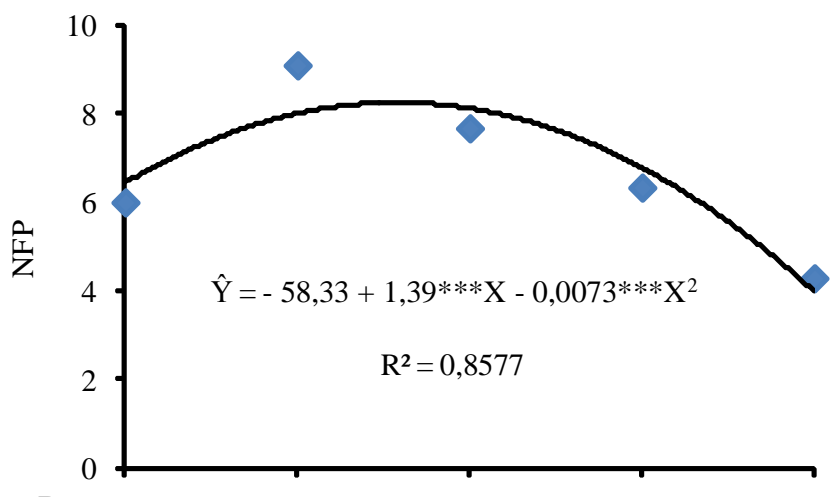

B.

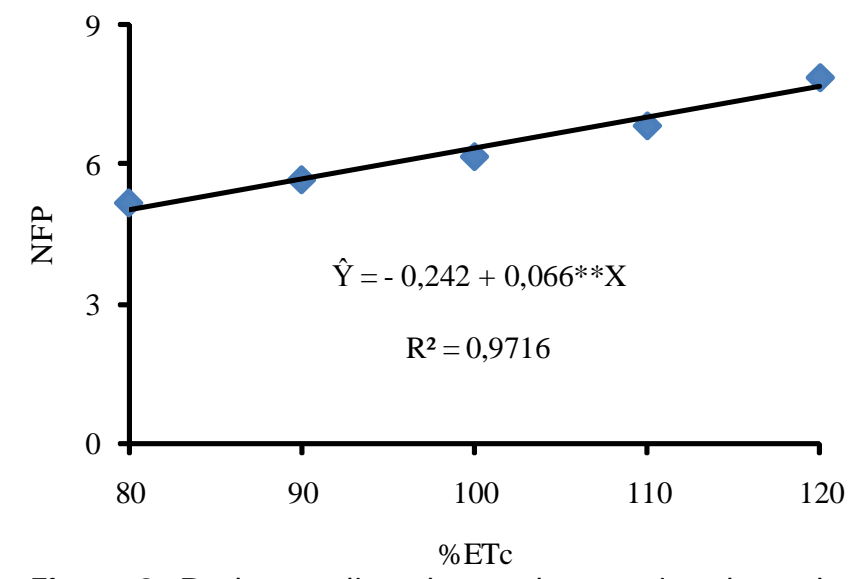

Figura 3. Dados médios observados e estimados pelo modelo no número de frutos por planta (N FP), em função de lâminas de irrigação, estimados nos níveis da dose de potássio $\mathrm{D}_{1}\left(80 \mathrm{~kg} \mathrm{ha}^{-1} \mathrm{~K}_{2} \mathrm{O}\right)(\mathrm{A})$ e dose de potássio $\mathrm{D}_{2}$ (120 kg ha-1 $\mathrm{K}_{2} \mathrm{O}$ ) (B)

Este resultado corroborou com os resultados encontrados por Melo et al. (2009), que observaram ajuste quadrático para o número de frutos, em função das doses crescentes de potássio, em estudos para avaliar o suprimento de potássio via fertigação na produção e na qualidade de frutos de pimentão híbrido amarelo cv. Zarco.

No segundo caso, que apresentou ajuste linear (Figura 3B), fixando-se a dose de potássio $120 \mathrm{~kg} \mathrm{ha}^{-1}\left(\mathrm{D}_{2}\right)$, observou-se incremento de $52,37 \%$ quando comparado com os valores obtidos na lâmina $L_{1}$ da $\% E T c$ de 5,03 frutos por planta, e na lâmina $L_{5}$ de 7,66 frutos por planta, confirmando as afirmações de Hassan \& Ramlan (1994), ao se referirem a um número maior de frutos devido à adubação potássica.

Na Figura 4A e B, tem-se a variação dos dados médios observados do peso médio de frutos (PMF), em que os dados estimados obtidos estão apresentados nas equações de regressão, em função da variação de lâminas crescentes de irrigação com base na evapotranspiração da cultura (\%ETc) e das doses de potássio.

O peso médio de frutos estimado foi igual a $73,21 \mathrm{~g}$, apresentando ajuste linear para a dose $\mathrm{D}_{1}$ de potássio e quadrático para a dose de $120 \mathrm{~kg} \mathrm{ha}^{-1}\left(\mathrm{D}_{2}\right)$ de potássio, conforme Figuras 4A e 4B.

No primeiro caso (Figura 4A), ocorreu incremento de 30,06\% ao se comparar com os dados obtidos com a lâmina $\mathrm{L}_{1}$ da \% ETc
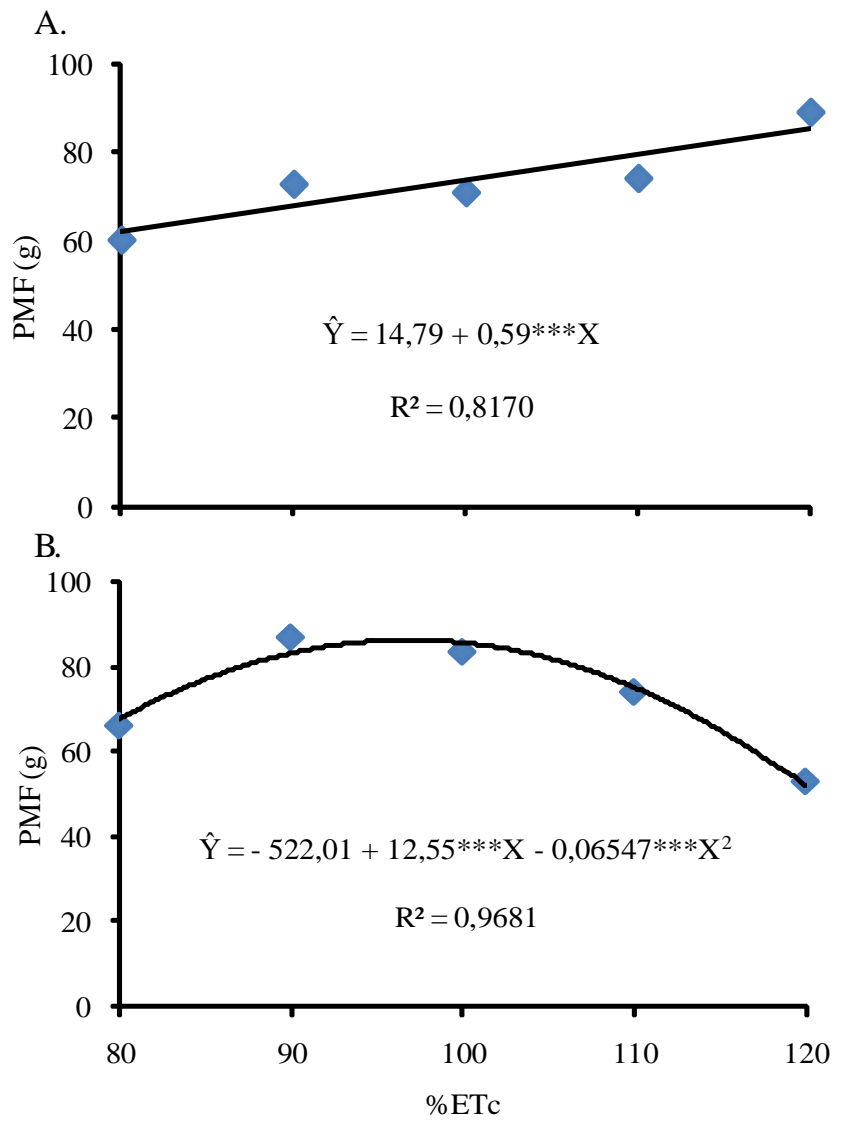

Figura 4. Dados médios observados e estimados pelo modelo no peso médio de frutos (PMF) em função de lâminas de irrigação, estimados nos níveis da dose de potássio $D_{1}\left(80 \mathrm{~kg} \mathrm{ha}^{-1} \mathrm{~K}_{2} \mathrm{O}\right)(\mathrm{A})$ e dose de potássio $\mathrm{D}_{2}$ (120 kg ha-1 $\left.\mathrm{K}_{2} \mathrm{O}\right)(\mathrm{B})$

de $61,93 \mathrm{~g}$ e a lâmina $\mathrm{L}_{5}$ de $85,50 \mathrm{~g}$, enquanto no segundo caso (Figura 4B), fixando-se a dose $\mathrm{D}_{2}$, pela derivada primeira da equação de regressão do peso médio de frutos, estimou-se a lâmina de $96,95 \%$ da ETc como aquela responsável pelo máximo peso médio de frutos; houve incrementos de 27,47 e 66,32\% quando se comparam os respectivos valores máximos estimados com os obtidos com a lâmina $\mathrm{L}_{1}$ de $67,67 \mathrm{~g}$, e a lâmina $\mathrm{L}_{5}$ de $51,86 \mathrm{~g}$.

Da mesma forma, Araújo et al. (2009b) encontraram ajustes lineares significativos para diâmetro, peso médio e número total de frutos, em função das doses crescentes de nitrogênio, ao avaliar aspectos relacionados às características de frutos de pimentão (var. All Big) cultivado sob diferentes doses de nitrogênio aplicadas via fertigação, em ambiente protegido.

Para a variável $P$, os respectivos modelos de regressão, conforme as Figuras $5 \mathrm{~A} \mathrm{e} \mathrm{B}$, indicaram relação quadrática para ambas as doses de potássio, nos níveis crescentes de lâminas de irrigação estudadas.

A produtividade média encontrada foi de $18,58 \mathrm{t} \mathrm{ha}^{-1}$. Pela derivada primeira das equações de regressão, estimaram-se as lâminas ótimas de 102,08\% da ETc para a dose $\mathrm{D}_{1}$ de potássio e 97,68\% da ETc para a dose $\mathrm{D}_{2}$ de potássio; essas lâminas proporcionaram máximas produtividades de 21,78 e 23,19 t ha ${ }^{-1}$, respectivamente.

Houve incrementos de 70,50 e 37,47\%, quando se comparam os respectivos dados estimados de produtividade (P) (máximo) 
A.

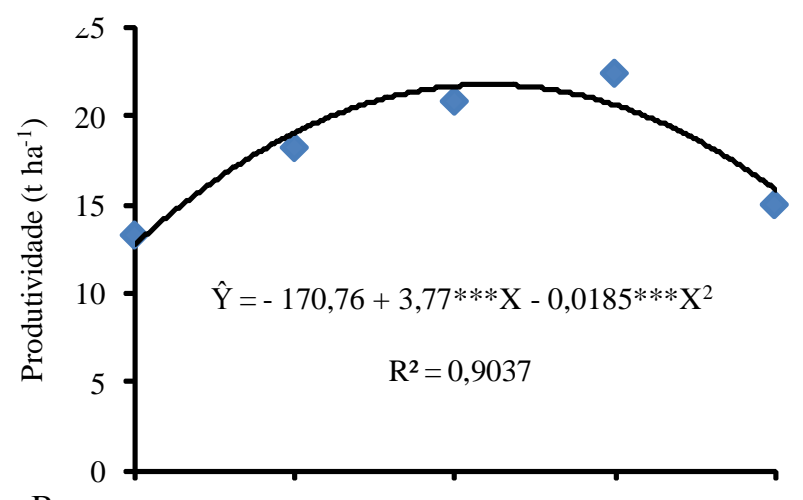

B.

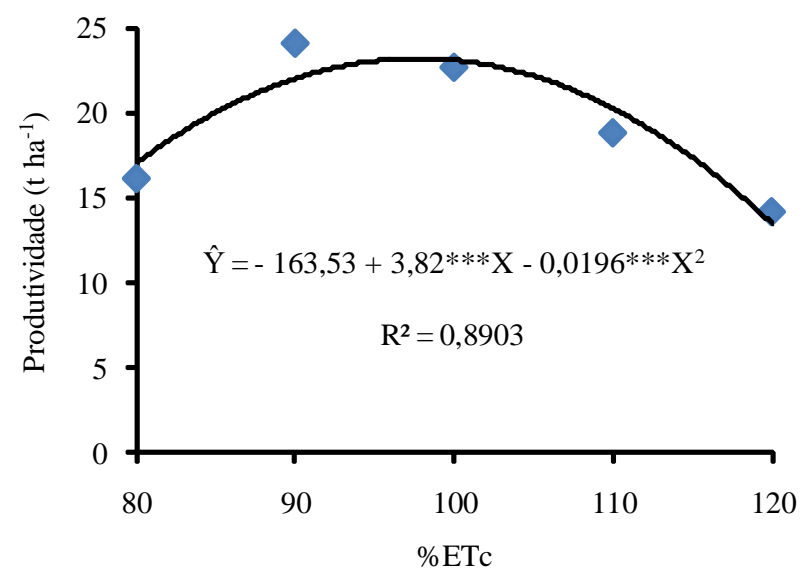

Figura 5. Dados médios observados e estimados pelo modelo na variável produtividade $(P)$ em função de lâminas de irrigação estimada nos níveis da dose de potássio $D_{1}\left(80 \mathrm{~kg} \mathrm{ha}^{-1} \mathrm{~K}_{2} \mathrm{O}\right)(\mathrm{A})$ e dose $D_{2}\left(120 \mathrm{~kg} \mathrm{ha}^{-1}\right.$ $\left.\mathrm{K}_{2} \mathrm{O}\right)(\mathrm{B})$

com aqueles obtidos com a lâmina $\mathrm{L}_{1}$ de 12,77 t ha-1 $\mathrm{e}$ a lâmina $\mathrm{L}_{5}$ de $15,84 \mathrm{t} \mathrm{ha}^{-1}$, fixando-se a dose $\mathrm{D}_{1}$ de potássio.

Para a dose $\mathrm{D}_{2}$, observaram-se incrementos de 35,82 e $72,61 \%$ quando se comparam os respectivos valores estimados de $\mathrm{P}$ (máximo) com aqueles obtidos com a lâmina $\mathrm{L}_{1}$ de 17,07 t ha $\mathrm{a}^{-1} \mathrm{e}$ a lâmina $\mathrm{L}_{5}$ de $13,43 \mathrm{t} \mathrm{ha}^{-1}$.

No segundo caso, a queda de produtividade ocorrida com a lâmina $\mathrm{L}_{5}$ deve ser explicada pelo estresse provocado pela maior lâmina e dose de potássio em excesso, proporcionando aumento da condutividade elétrica do meio, além da lixiviação de nutrientes, causando queda no rendimento das plantas.

Os resultados encontrados foram diferentes dos indicados por Araújo et al. (2009a), que observaram ajuste linear significativo para o rendimento total, com valor máximo próximo de $45 \mathrm{t} \mathrm{ha}^{-1}$, em função das doses crescentes de nitrogênio ao avaliarem a produção de frutos de pimentão, obtidos de plantas fertirrigadas com diferentes doses de nitrogênio cultivadas em ambiente protegido.

Blanco \& Folegatti (2008), avaliando a produção e a qualidade de frutos de tomate sob diferentes doses de $\mathrm{N}$ e K aplicados via fertigação por gotejamento, não verificaram efeito dos tratamentos sobre a produtividade, tamanho e peso médio dos frutos.

\section{CONCLusões}

1. As variáveis de crescimento e de rendimento de frutos do pimentão foram influenciadas pelas doses de potássio e pelas lâminas de irrigação aplicadas, mostrando a interação do efeito da água com fertilizantes nas respostas das variáveis.

2. As lâminas de irrigação e as doses de potássio aplicadas determinaram a fenologia da cultura do pimentão nessas condições experimentais, representada pela altura de plantas e o diâmetro do colo, medidos ao longo dos dias de observação, cujos dados alternaram ajustes lineares e quadráticos.

3. O maior índice de área foliar ocorreu quando foi aplicada a lâmina de irrigação de $120 \%$ da evapotranspiração da cultura, estimado em ambas as doses de potássio aplicadas.

4. Quando se fixou a menor dose, a estimativa do maior número de frutos por planta, peso médio de frutos e produtividade, ocorreram com o emprego da lâmina de irrigação de máxima eficiência de 96, 120 e 102\% da evapotranspiração da cultura, respectivamente; quando se fixou a maior dose, a estimativa do maior número de frutos por planta, peso médio de frutos e produtividade, ocorreram com o emprego da lâmina de irrigação de máxima eficiência de 120, 97 e 98\% da evapotranspiração da cultura, respectivamente.

5. Recomenda-se, nestas condições, para alcançar rendimentos satisfatórios, aplicar uma lâmina de irrigação próxima dos $100 \%$ da evapotranspiração da cultura e dose de $80 \mathrm{~kg} \mathrm{ha}^{-1}$ de $\mathrm{K}_{2} \mathrm{O}$.

\section{LITERATURA CITADA}

Albuquerque Filho, J. A. C. de; Lima, V. L. A. de; Menezes, D.; Azevedo, C. A. V. de; Dantas Neto, J.; Silva Júnior, J. G. da. Características vegetativas do coentro submetido a doses do polímero hidroabsorvente e lâminas de irrigação. Revista Brasileira de Engenharia Agrícola e Ambiental, v.13, p.671679, 2009.

Alvarez V. V.; H.; Alvarez, G. A. M. Apresentação de equações de regressão e suas interpretações. Boletim Informativo da Sociedade Brasileira de Ciência do Solo, v.28, p.28-32, 2003.

Araújo, J. S.; Andrade, A. P. de; Ramalho, C. I.; Azevedo, C. A. V. de. Cultivo do pimentão em condições protegidas sob diferentes doses de nitrogênio via fertirrigação. Revista Brasileira de Engenharia Agrícola e Ambiental, v.13, p.559565, 2009a.

Araújo, J. S.; Andrade, A. P. de; Ramalho, C. I.; Azevedo, C. A. V. de. Características de frutos de pimentão cultivado em ambiente protegido sob doses de nitrogênio via fertirrigação. Revista Brasileira de Engenharia Agrícola e Ambiental, v.13, p.152-157, 2009b.

Bernardo, S; Soares, A. A.; Mantovani, E. C. Manual de irrigação. 8.ed. Viçosa: UVF, 2008. 625p.

Blanco, F. F; Folegatti, M. V. Doses de N e K no tomateiro sob estresse salino: III. Produção e qualidade de frutos. Revista Brasileira de Engenharia Agrícola e Ambiental, v.12, p.122$127,2008$.

Doorenbos, J.; Pruitt, W. O. Crop water requirements. Rome: FAO, 1977. 179p. Irrigation and Drainage Paper, 24 
Echer, M. M.; Fernandes, M. C. A.; Ribeiro, R. L. D.; Peracchi, A. L. Avaliação de genótipos de Capsicum para resistência a ácaro branco. Horticultura Brasileira, v.20, p.217-221, 2002.

Eloi, W. M.; Souza, V. F. de; Viana, T. V. de A.; Andrade Júnior, A. S. de; Holanda, R. S. F. de; Alcântara, R. M. C. M. de. Distribuição espacial do sistema radicular da gravioleira em função de doses de nitrogênio e potássio aplicados via fertirrigação. Irriga, v.9, p.256-69, 2004.

Ferreira, D. F. SISVAR: Um programa para análises e ensino de estatística. Revista Symposium, v.6, p.36-41, 2008.

Hassan, S. A.; Ramlan, Z. A. Influence of potassium fertilizer and mulching on growth and yield of chilli (Capsicum annиum L.). Acta Horticulture, v.369, p.311-318, 1994.

Macêdo, L. de S.; Alvarenga, M. A. R. Efeitos de lâminas de água e fertirrigação potássica sobre o crescimento, produção e qualidade do tomate em ambiente protegido. Ciência e Agrotecnologia, v.29, p.296-304, 2005.

Marcussi, F. F. N. Uso da fertirrigação e teores de macronutrientes em planta de pimentão. Engenharia Agrícola, v.25, p.642-650, 2005.

Medeiros, G. A.; Arruda, F. B.; Sakai, E. Relações entre o coeficiente de cultura e cobertura vegetal do feijoeiro: Erros envolvidos e análises para diferentes intervalos de tempo. Acta Scientiarum, v.26, p.513-519, 2004.

Melo, A. S. de; Brito, M. E. B.; Dantas, J. D. de M.; Silva Júnior, C. D. da; Fernandes, P. D.; Bonfim, L. V. Produção e qualidade do pimentão amarelo sob níveis de potássio em ambiente protegido. Revista Brasileira de Ciências Agrárias, v.4, p.1721, 2009.
Nanetti, D. C.; Souza, R. J. de; Faquin, V. Efeito da aplicação de nitrogênio e potássio, via fertirrigação, na cultura do pimentão. Horticultura Brasileira, v.18, p.843-845, 2000.

Oliveira, M. V. A. M. de; Villas Bôas, R. L. Uniformidade de distribuição do potássio e do nitrogênio em sistema de irrigação por gotejamento. Engenharia Agrícola, v.28, p.95-103, 2008.

Papadopoulos, I. Fertigation: Present situation and future prospects. In: Folegatti, M. V. (coord.). Fertirrigação: Citrus, flores, hortaliças. Guaíba: Agropecuária, 1999. Cap.1, p.85-154.

Pizarro, F. Riegos localizados de alta frecuencia (RLAF): Goteo, microaspersión, exudácion. 3.ed. Madrid: Ediciones MundiPrensa, 1996. 511p.

Rezende, F. C.; Frizzone, J. A.; Pereira, A. S.; Botrel, T. A. Plantas de pimentão cultivadas em ambiente enriquecido com $\mathrm{CO}_{2}$. II. Produção de matéria seca. Acta Scientiarum, v.24, p.15271533, 2002.

Silva, M.A. G.; Boaretto, A. E.; Fernandes, H. G.; Boaretto, R. M.; Melo, A. M. T.; Scivittaro, W. B. Características químicas de um latossolo adubado com uréia e cloreto de potássio em ambiente protegido. Scientia Agrícola, v.58, p.561-566, 2001.

Subhani, P.M.; Ravisankar, C.; Narayana, N. Effect of graded levels and time of application of $\mathrm{N}$ and $\mathrm{K}_{2} \mathrm{O}$ on flowering, fruiting and yield of irrigated chilli. Indian Cocoa - Arecanut and Spices Journal, v.14, p.70-73, 1990.

Trani, P. E.; Carrijo, O. A. Fertirrigação em hortaliças. Campinas: Instituto Agronômico, 2004. 53p. (Boletim Técnico, 196).

Vanangamudi, K.; Subramanian, K. S.; Baskaran, M. Influence of irrigation and nitrogen on the yield and quality of chilli fruit and seed. Seed Research, v.18, p.114-116, 1990. 